
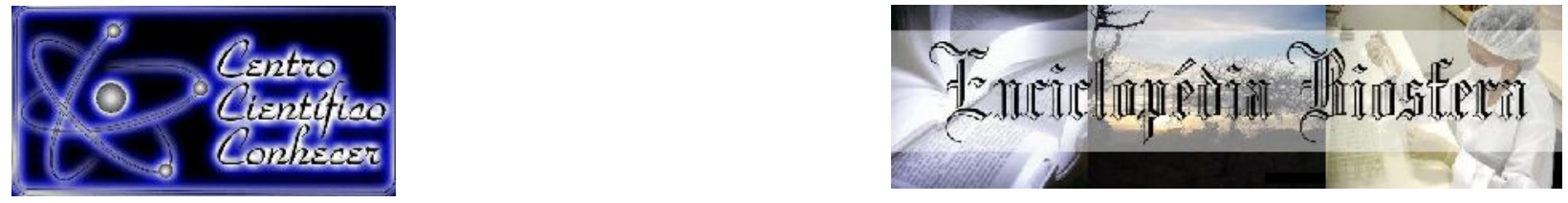

\title{
ANÁLISE MICROBIOLÓGICA DE SORVETE EXPRESSO COMERCIALIZADOS EM UBERLÂNDIA, MINAS GERAIS, BRASIL
}

\author{
Caroline Weber ${ }^{1}$, Kênia de Fátima Carrijo ${ }^{2}$ \\ ${ }^{1}$ Médica Veterinária graduada pela Universidade Federal de Uberlândia \\ (carolwvet1@gmail.com), Uberlândia-MG, Brasil. \\ ${ }^{2}$ Professora Doutora da Universidade Federal de Uberlândia \\ Recebido em: 22/09/2018 - Aprovado em: 23/11/2018 - Publicado em: 03/12/2018 \\ DOI: 10.18677/EnciBio_2018B6
}

\begin{abstract}
RESUMO
O sorvete expresso (soft ou italiano) é classificado como um sorvete de massa aerada ou cremosa, obtido a partir de uma mistura homogênea, batido, resfriado e congelado. Por ser um derivado de leite, que pode conter ainda, diversos outros ingredientes, é um excelente substrato para a multiplicação bacteriana, sendo que, muitos destes microrganismos sobrevivem às baixas temperaturas empregadas no processo de congelamento. Aliado a este fato, podem ocorrer variações de temperatura durante o processo de produção até chegar ao final da cadeia produtiva, representado pelo consumidor final. Portanto, a alta contagem ou simplesmente a presença desses microrganismos, podem ocasionar nos consumidores, toxinfecções alimentares. Assim, é necessário um controle higiênicosanitário em todas as etapas de sua elaboração, por meio da aplicação das boas práticas de fabricação e monitoramento do processo produtivo. Assim, este trabalho teve como objetivo avaliar, do ponto de vista microbiológico (bactérias aeróbias mesófilas, coliformes totais e coliformes termotolerantes), sorvetes expresso comercializados em Uberlândia, Minas Gerais, Brasil, a fim de verificar sua qualidade microbiológica. Foram coletadas 18 amostras de sorvete pronto ao consumo e uma calda crua, totalizando 19 amostras. Com relação a contagens de bactérias mesófilas, 10 das amostras avaliadas $(52,6 \%)$ e 6 delas $(31,58 \%)$ estariam não conformes para coliformes totais, segundo padrões microbiológicos internacionais, além de 6 amostras (57,9\%) serem consideradas impróprias para o consumo, segundo a ANVISA. A qualidade microbiológica dos sorvetes expresso comercializados em Uberlândia, Minas Gerais, Brasil analisados apresentaram qualidade microbiológica insatisfatória, o que pode ocasionar eminente risco à saúde da população consumidora.
\end{abstract}

PALAVRAS-CHAVE: derivados lácteos, Gelados comestíveis, microbiologia de alimentos.

\section{MICROBIOLOGICAL ANALYSIS OF EXPRESS ICE CREAM SOLD IN UBERLANDIA CITY, MINAS GERAIS, BRAZIL}

\begin{abstract}
Express ice cream (soft or Italian) is classified as a mass aerated ice cream or creamy, obtained from a homogeneous mixture, beaten, cold and frozen. Because it is a dairy product, which may also include various other ingredients, including milk, is
\end{abstract}


a great substrate for bacterial multiplication, and many of these microorganisms survive the low temperatures employed in the freezing process. Allied to this fact may occur in temperature during the production process until you reach the end of the production chain, represented by the final consumer. Therefore, the high score or simply the presence of these microorganisms can cause foodborne diseases in consumers of greater or lesser severity. So, we need a hygienic-sanitary control at all stages of the preparation of these foods, through the application of good manufacturing practices and finds monitoring the entire production process. This work aimed to evaluate, from a microbiological point of view (mesophilic aerobic bacteria, total coliforms and thermotolerant coliforms) expressed ice cream sold in Uberlandia, Minas Gerais, Brazil, in order to verify its microbiological quality. With respect to mesophilic bacteria counts of 10 samples $(52.6 \%)$ and 6 of them $(31.58 \%)$ were non-compliant for total coliforms according to international microbiological standards, and sample 6 (57.9\%) were considered unfit for consumption according to ANVISA. The microbiological quality of ice cream marketed expressed in Uberlandia, Minas Gerais, Brazil analyzed in this study showed unsatisfactory microbiological quality, which may cause imminent risk to the health of consumers.

KEYWORDS: dairy products, edible ices, food microbiology.

\section{INTRODUCÃO}

Segundo a Agência Nacional de Vigilância Sanitária (ANVISA) do Ministério da Saúde, sorvetes são os produtos elaborados basicamente com leite e ou derivados lácteos e ou outras matérias-primas alimentares, nos quais os teores de gordura e ou proteína são total ou parcialmente de origem não láctea, podendo ser adicionados de outros ingredientes alimentares (BRASIL, 2000). A mistura para a elaboração do sorvete deve ser homogênea e pasteurizada, e por meio da agitação contínua do leite e dos ingredientes adicionados, o ar é incorporado à mistura, dando textura suave e macia ao produto congelado (DEOSARKAR et al., 2016). Trata-se, portanto, de um produto gelado comestível.

Segundo a ANVISA, os produtos gelados comestíveis são ordenados pelo seu processo de fabricação e forma de apresentação; sendo assim, o sorvete expresso (soft ou italiano) é classificado como sorvete de massa aerada ou cremosa, obtido a partir de uma mistura homogênea, batido, resfriado e congelado (RICHARDS, 2002).

Em relação ao leite, o sorvete possui índices superiores de nutrientes, cerca de $12 \%$ a $16 \%$ a mais de proteína, três a quatro vezes mais gordura, quatro vezes mais carboidratos, além de ferro e outros minerais, sendo considerado um alimento nutritivo (SOUKOULIS et al., 2014; BAHRAM-PARVAR, 2015; BALTHAZAR et al., 2017).

Devido às características intrínsecas, o leite por possuir o $\mathrm{pH}$ próximo ao neutro, alto teor de água e pela gama de nutrientes nele presentes, é ótimo substrato para multiplicação de microrganismos, que podem advir de diversas origens, como ordenha, problemas de transporte, manipulação, processamento e armazenamento (CLAYES et al., 2013). Por conseguinte, explica-se a enorme importância da qualidade deste leite que será utilizado na elaboração de seus derivados.

O sorvete sendo derivado de leite, que pode conter diversos outros ingredientes, é ótimo substrato para a multiplicação bacteriana, sendo que, muitos destes microrganismos sobrevivem às baixas temperaturas empregadas no processo de congelamento. Aliado a este fato podem ocorrer variações de 
temperatura durante o processo de produção até chegar ao final da cadeia produtiva, representado pelo consumidor final. Portanto, a alta contagem ou simplesmente, a presença desses microrganismos pode ocasionar nos consumidores toxinfecções alimentares, de maior ou menor gravidade. Assim, representam uma grande preocupação para a indústria de laticínios, bem como autoridades de saúde pública (MELO et al., 2015), já tendo sido relatados na literatura, diversos surtos de doenças alimentares relacionados ao consumo de sorvetes (FETSCH et al., 2014; CDC, 2015; POUILLOT et al., 2016). Diante do exposto, deve-se ressaltar que é necessário um controle higiênico-sanitário em todas as etapas da elaboração destes alimentos, por meio da aplicação das boas práticas de fabricação e monitoramento constante de todo o processo produtivo.

Assim, diante do exposto, este trabalho teve como objetivo avaliar, do ponto de vista microbiológico, sorvetes expresso comercializados em Uberlândia, Minas Gerais, Brasil, a fim de verificar sua qualidade microbiológica.

\section{MATERIAL E MÉTODOS}

As amostras avaliadas foram coletadas em diversos estabelecimentos comercias de fabricação e venda de sorvete expresso (italiano ou soft) e com grande circulação de consumidores na cidade de Uberlândia, Minas Gerais, Brasil, entre os meses de setembro a novembro de 2015. Foram analisadas 19 amostras, sendo 18 de sorvetes prontos para o consumo (sabor baunilha e creme) e uma amostra de calda crua para o preparo deste tipo de sorvete, retirada direto da embalagem do fabricante.

As amostras foram adquiridas na condição de consumidor e após a coleta, estas foram acondicionadas em frascos plásticos estéreis e transportadas congeladas em caixas de isopor. Todas as amostras foram previamente etiquetadas, com finalidade de identificação.

As amostras foram encaminhadas imediatamente para o Laboratório de Tecnologia e Inspeção de Produtos de Origem Animal da Faculdade de Medicina Veterinária da Universidade Federal de Uberlândia. As amostras foram acondicionadas em refrigerador, regulado a uma temperatura de $7^{\circ} \mathrm{C}$ para se liquefazerem, a fim de se proceder a seguir, a realização das diluições (SILVA et al., 2017).

A seguir as amostras foram processadas para que se procedesse à pesquisa de coliformes totais, coliformes termotolerantes (coliformes a $45^{\circ} \mathrm{C} / \mathrm{g}$ ), e a contagem de bactérias heterotróficas aeróbias mesófilas, adotando a metodologia descrita na Instrução Normativa №62/2003 (BRASIL, 2003), do Ministério da Agricultura, Pecuária e Abastecimento (MAPA), que estabelece os métodos analíticos oficiais para análises microbiológicas para controle de produtos de origem animal e água.

A retirada da unidade analítica $(25 \mathrm{ml})$ de cada amostra foi realizada com 0 auxílio de espátulas estéreis, as quais foram medidas individualmente em condições assépticas. As mesmas foram homogeneizadas em $225 \mathrm{~mL}$ de solução salina peptonada (SSP) a 0,1\% em "Stomacher" durante 60 segundos. A partir da diluição inicial $\left(10^{-1}\right)$, efetuou-se as demais diluições sucessivas em solução salina peptonada 0,1 até $10^{-5}$ (BRASIL, 2003).

Para o cultivo de microrganismos aeróbios mesófilos foi semeado $1 \mathrm{~mL}$ de cada diluição em placas de Petri estéreis, em duplicata. A seguir, adicionou-se cerca de 15 a $20 \mathrm{~mL}$ de PCA fundido e mantido em banho-maria a 46-48으. Foi realizada a homogeneização do ágar com o inóculo, o qual foi deixado para solidificar em superfície plana. Inverteram-se as placas, as quais foram incubadas a $36 \pm 1^{\circ} \mathrm{C}$ por 
48 horas (BRASIL, 2003). Para a leitura, foram selecionadas placas que continham entre 25 e 250 colônias. Procedeu-se a contagem, cujos resultados foram expressos em unidades formadoras de colônias por $\mathrm{mL}$ (UFC/mL).

Para a enumeração de coliformes totais e termotolerantes, adotou-se a técnica do Número Mais Provável (BRASIL, 2003). Para a prova presuntiva, as amostras foram inoculadas em caldo lauril sulfato de sódio, na quantidade de $1 \mathrm{~mL}$ das diluições $10^{-1}, 10^{-2}$ e $10^{-3}$, em séries de três tubos. A presença de coliformes foi comprovada pela formação de gás nos tubos de Durhan invertidos, após a incubação em estufa a $36 \pm 1^{\circ} \mathrm{C}$ por 48 horas. Para a confirmação da presença de coliformes totais, foi feita a transferência das culturas dos tubos positivos da prova presuntiva, para tubos que continham caldo verde brilhante bile lactose $2 \%$ e posterior incubação a $36 \pm 1^{\circ} \mathrm{C}$ por 48 horas (Figura 1). Tendo a presença de gás no interior dos tubos de Durhan ou efervescência após leve agitação, o resultado foi considerado positivo, pois a lactose presente no meio foi fermentada.

Coliformes termotolerantes foram evidenciados através de repique dos tubos positivos obtidos na prova presuntiva em Caldo EC e incubação seletiva a $45 \pm$ $0,2^{\circ} \mathrm{C}$ por 48 horas em banho maria com agitação (Figuras 2 e 3). Neste caso, também foi considerado positivo, quando evidenciava-se a presença de gás nos tubos de Durhan ou efervescência seguida de leve agitação. Os tubos positivos para cada uma das diluições foram anotadas para o posterior cálculo do Número Mais Provável (NMP) por $\mathrm{mL}$ de amostra, fazendo uso da tabela de Mac Crady, aplicando-se a seguinte fórmula:

NMP $=\underline{\text { NMP da tabela } x \text { fator de diluição intermediária } x \text { fator de correção (10) }}$ 100

Os resultados das análises microbiológicas de sorvete expresso (italiano ou soft) foram agrupados, dispostos em quadros e analisados por meio da estatística descritiva e frequência simples.

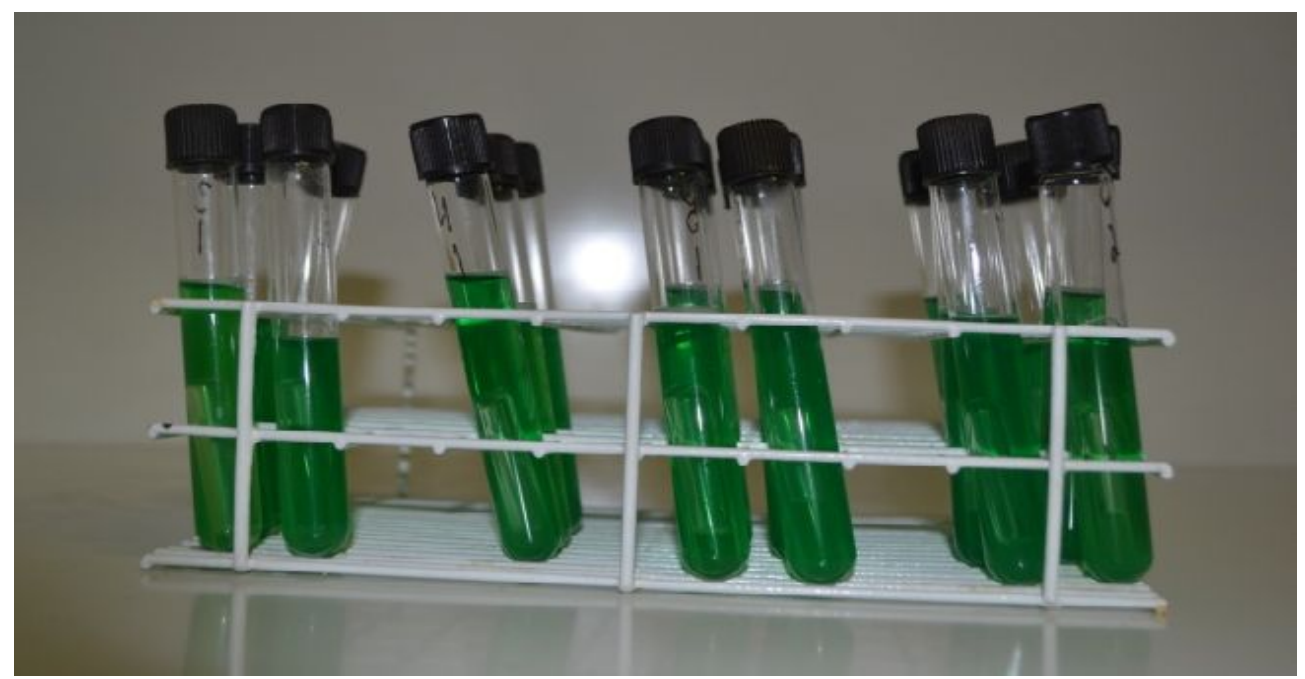

FIGURA 1 - Séries de tubos em caldo Verde Brilhante verde lactose $2 \%$. Fonte: Arquivo pessoal 


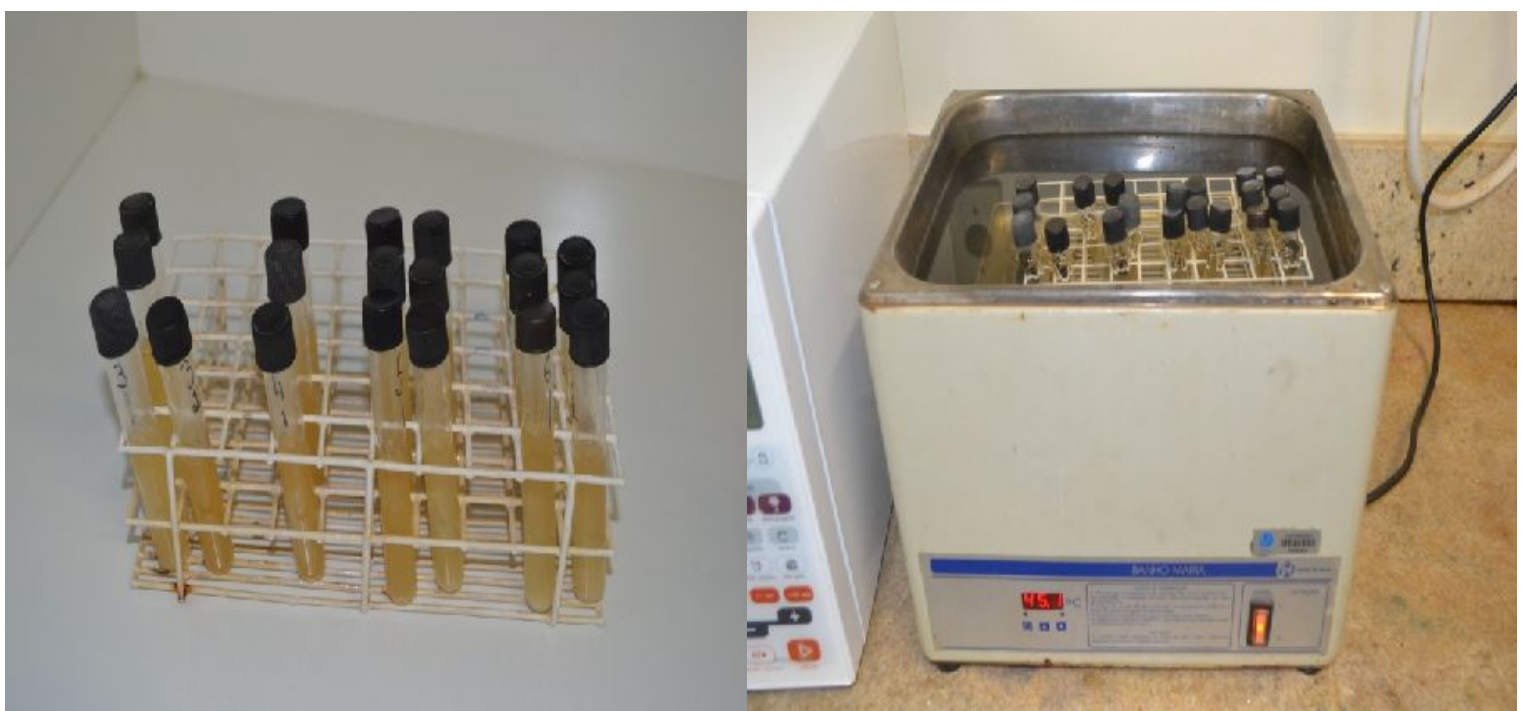

FIGURA 2 - Séries de tubos com caldo EC. FIGURA 3 - Amostras em incubação à $45^{\circ} \mathrm{C}$. Fonte: Arquivo pessoal

\section{RESULTADOS E DISCUSSÃO}

No quadro 1, estão relacionadas as contagens de microrganismos aeróbios mesófilos (UFC/mL). Verifica-se, que as contagens variaram de $<10$ a $2,3 \times 10^{7}$ $\mathrm{UFC} / \mathrm{mL}$. As amostras 04 e 06 foram as que apresentaram as maiores contagens, seguidas das amostras 05 e 02.

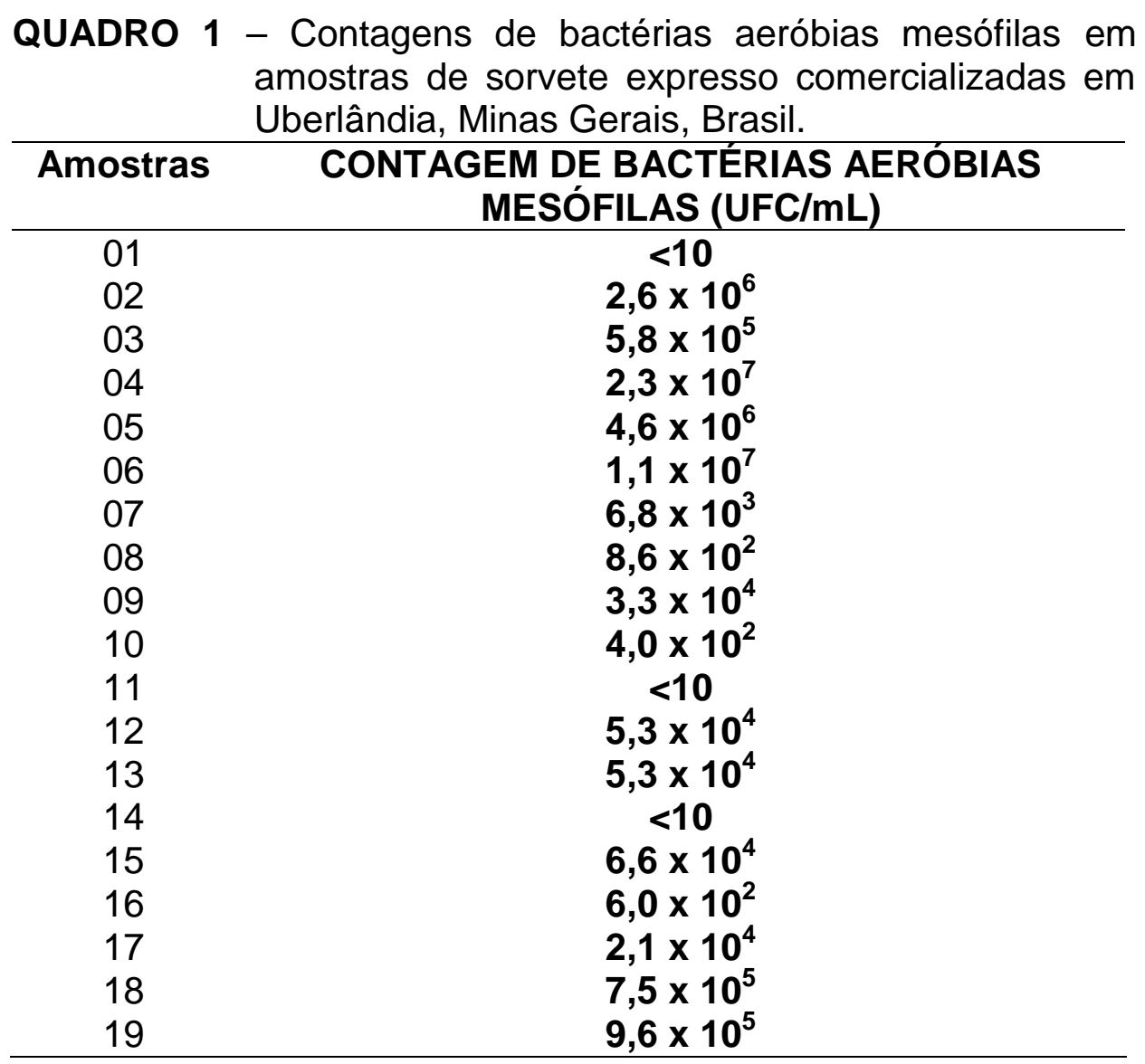


A RDC $n^{\circ} 12 / 2001$ da ANVISA (BRASIL, 2001), não estabelece padrão microbiológico para gelados comestíveis produzidos no Brasil. No entanto, de acordo com o Kenya Bureau of Standards (KEBS), que estabelece os requisitos, métodos de ensaio e padrões microbiológicos e físico-químicos para gelados comestíveis prontos para consumo, além de misturas para preparação de sorvetes em forma líquida ou em pó, a contagem de aeróbios mesófilos deve ser de no máximo 50 000/ UFC/mL (5 x $\left.10^{4} \mathrm{UFC} / \mathrm{ml}\right)$ (KEBS, 2013). Esta é também contagem máxima estabelecida pela ISI (Indian Standard Institution) e pela Frozen Confections Regulation de Hong Kong para gelados comestíveis, quanto a este grupo de microrganismos (ISI, 1964; FROZEN CONFECTIONS REGULATION, 2014). Assim, de acordo com estes padrões, 10 das amostras analisadas (52,6\%) estariam inadequadas para o consumo humano (amostras 2, 3, 4, 5, 6, 12, 13, 15, 18 e 19).

Silva et al. (2017), afirmam que embora, a contagem total de aeróbios mesófilos em placas, seja um importante indicador de populações bacterianas nos alimentos, o meio de cultura utilizado nesta análise, não seleciona especificamente determinados grupos de bactérias, e por isto, é utilizada para obter-se informações sobre a qualidade, práticas de produção, matérias-primas, processamento, manipulação e vida útil dos produtos alimentícios. Neste sentido, Allata et al. (2017) afirmam que altas contagens de bactérias aeróbias mesófilas em sorvete, indicam a utilização de matéria-prima contaminada, limpeza e desinfecção de superfícies inadequadas, higiene insuficiente nas operações ou a combinação dessas circunstâncias.

No presente trabalho, as amostras 04 e 06, que foram aquelas que apresentaram maiores contagens, embora fossem de diferentes quiosques de comercialização de sorvete expresso, estes estavam localizados num mesmo terminal rodoviário de transporte coletivo urbano, sugerindo que a fonte de contaminação do sorvete pode ter algo em comum, como por exemplo, a água de abastecimento utilizada na higienização do maquinário e dos utensílios que entram em contato com o sorvete. Como não foi avaliada a qualidade microbiológica da água dos estabelecimentos, não é possível ter certeza, se de fato foi esta a provável fonte de contaminação.

No quadro 2, encontra-se a enumeração para coliformes totais e coliformes termotolerantes $(\mathrm{NMP} / \mathrm{mL})$ nas amostras de sorvete expresso analisadas. As amostras que apresentaram maior população de coliformes totais, foram as de número 02 e 07 . Estas amostras também foram as que apresentaram maiores populações microbianas para coliformes termotolerantes (NMP/mL).

Não há padrão para coliformes totais em sorvetes no Brasil. No entanto, em Hong Kong, a Frozen Confections Regulation estabelece em seu regulamento que sorvetes comercializados no varejo, não devem conter mais de 100 coliformes $(1,0 \mathrm{x}$ $10^{2}$ ) por grama (FROZEN CONFECTIONS REGULATION, 2014). Assim, segundo este regulamento, 6 das amostras analisadas (31,58\%), não estariam conformes. $O$ Turkish Standards Institute, também estabelece que para gelados comestíveis, a contagem de coliformes deve ser inferior a 100 UFC/g (ICE CREAM STANDARD, 1992).

Segundo a RDC n. 12/2001 da ANVISA (BRASIL, 2001), para gelados comestíveis e produtos para o preparo de gelados comestíveis, é estabelecida uma tolerância para coliformes termotolerantes de até $5 \times 10 \mathrm{NMP} / \mathrm{mL}$, sendo que, quando a enumeração é superior a este padrão, o sorvete é considerado impróprio para o consumo. Assim, diante deste padrão, 6 amostras (57,9\%) são consideradas 
impróprias para o consumo, por apresentarem condições higiênico-sanitárias insatisfatórias (amostras 2, 5, 7, 12, 13 e 18).

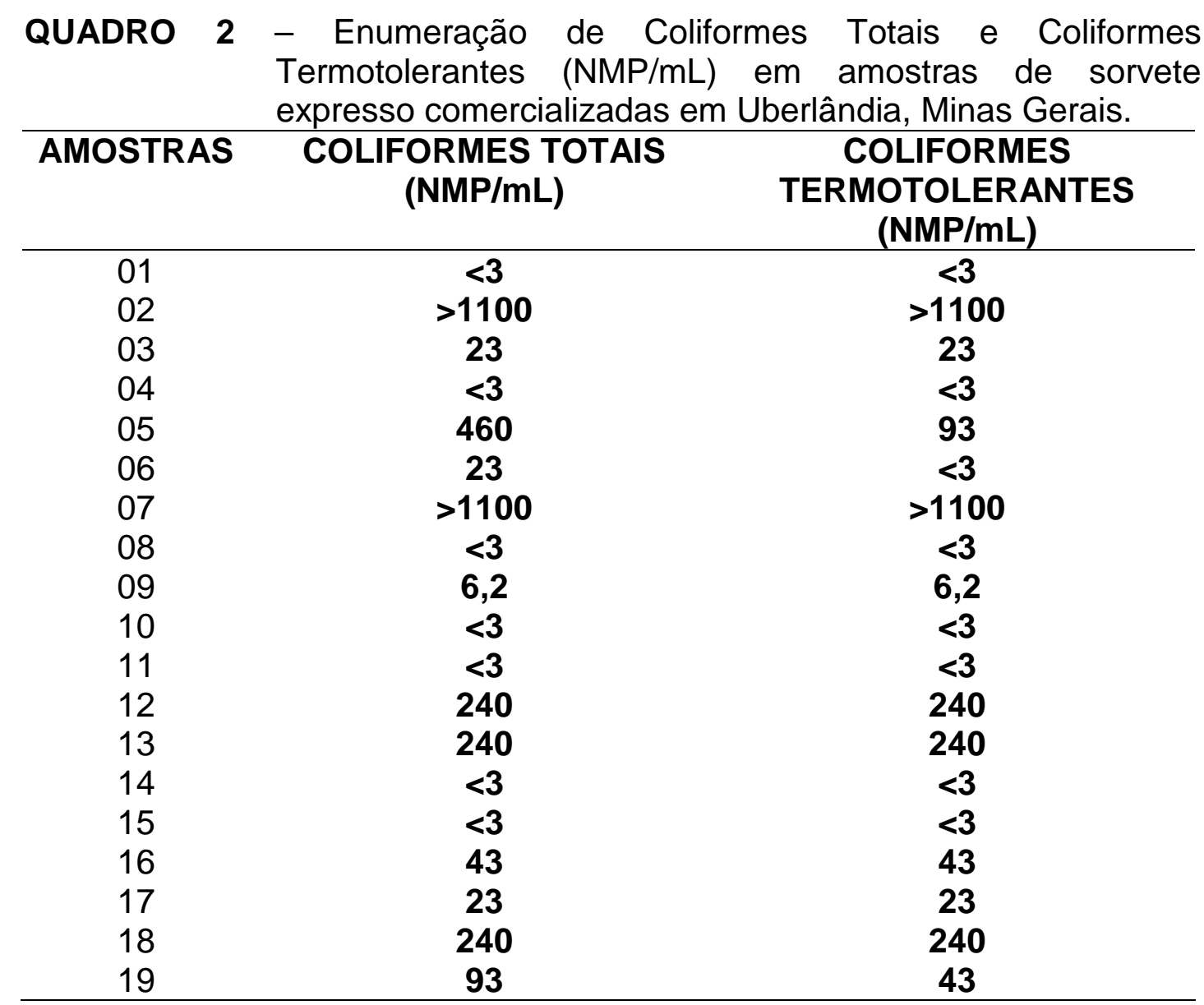

Microrganismos do grupo Coliformes são os principais colonizadores do trato gastrointestinal de seres humanos e são indicadores das condições higiênicosanitárias de alimentos, indicando erros na manipulação do produto. São bactérias que pertencem as enterobactérias, sendo Gram negativas e anaeróbias facultativas, apresentando-se em formas de bastonetes, não esporuladas, capazes de fermentar a lactose produzindo ácido e gás, à temperatura de $35^{\circ} \mathrm{C}$ de 24 a 48 horas (SILVA et al., 2017).

Contagens altas de coliformes totais sugerem a possibilidade de contaminação pós-processamento, limpeza e sanitização inadequadas ou o conjunto desses fatores (PAPADEMAS; BINTISIS, 2010). Com relação às amostras que apresentaram as maiores enumerações de coliformes termotolerantes, no ponto de venda da amostra 02, foi verificado que não havia pia para higienização, tanto das mãos do manipulador, quanto para a higienização da máquina, que deveriam ser realizados em outro local. Além disso, o único funcionário do local era quem preparava e entregava o sorvete para o consumidor e em seguida, recebia 0 pagamento pelo sorvete. Tal situação favorece a contaminação cruzada do produto. Já no ponto de venda da amostra 07, verificou-se que embora esta apresentasse infraestrutura adequada para a manipulação e comercialização de gelados comestíveis, o sorvete na ocasião da aquisição, não apresentava consistência firme, pelo fato da calda base não ter sido adequadamente resfriada, a ponto de formar gelo, cuja baixa temperatura é fundamental para a elaboração e conservação do 
sorvete. Allata et al. (2017) acrescentam ainda, que para evitar o crescimento de qualquer bactéria termotolerante potencialmente presente, é essencial que no processo de produção do sorvete, este seja resfriado, imediatamente após o processamento térmico, reduzindo a temperatura de 80 para $4^{\circ} \mathrm{C}$ em um intervalo de 1 hora. Assim, presume-se que a grande quantidade de coliformes, tanto totais quanto termotolerantes, apresentadas no presente estudo, podem estarem relacionadas com a manutenção da massa do sorvete em temperatura superior à recomendada, ou ainda, ao não resfriamento no tempo e temperatura apropriada, recomendados.

$\mathrm{Na}$ amostra de número 19, foi avaliada a qualidade microbiológica de uma calda de sorvete, antes do contato com a máquina. A coleta do produto foi realizada diretamente da embalagem do fabricante. Foi possível verificar a má qualidade sanitária desta matéria prima, que entra na composição de sorvetes, já que a calda inicial apresentava elevada quantidade de microrganismos. Esta calda, normalmente é utilizada por diferentes estabelecimentos que elaboram e comercializam sorvete expresso, por ser um produto industrializado e prático, agilizando o seu preparo. É importante questionar a fonte desta contaminação, de tal forma, que pode-se questionar sobre a abordagem de abertura da embalagem e uma possível contaminação cruzada.

Os resultados obtidos atestam a qualidade insatisfatória dos sorvetes expresso comercializados nos pontos de venda visitados em Uberlândia e indicam as condições higiênicas que este produto foi produzido e ou/manipulado. Por ser um alimento que passa por um processo de pasteurização, realizado de forma correta, presume-se que tais microrganismos foram destruídos pela pasteurização. Pode-se, portanto, associar as elevadas populações observadas neste estudo, com a recontaminação do produto ocorrida durante as etapas do processamento subsequentes à pasteurização. Evidencia-se, dessa forma, a deficiência nas condições higiênico-sanitárias dos estabelecimentos envolvidos na comercialização dos sorvetes, sugerindo, contato com conteúdo fecal, seja através de matéria-prima ou de equipamentos mal higienizados, ou de manipulação higiênica inadequada. Deve-se ainda, atentar às condições pós-processamento, sobretudo, a manutenção da temperatura de refrigeração indicada para a conservação do produto.

Para prevenir ou eliminar a hipótese de que ingredientes se tornem fonte de contaminação e proliferação bacteriana, além de outros riscos eminentes, deve-se ter uma vigilância efetiva e sistemática para a qualidade das matérias-primas utilizadas na fabricação de produtos para garantir a qualidade do produto ofertado.

\section{CONCLUSÃO}

A qualidade microbiológica dos sorvetes expresso comercializados em Uberlândia, Minas Gerais, Brasil, analisados na presente pesquisa, apresentaram qualidade microbiológica insatisfatória, o que pode ocasionar eminente risco à saúde da população consumidora. Assim, a capacitação dos manipuladores para a adequada aplicação das boas práticas de produção e manipulação, adequada higienização dos equipamentos, controles de tempo e temperatura do produto, são fundamentais para que as contagens das populações microbianas pesquisadas sejam menores. Aliado a isso, uma fiscalização mais efetiva por parte dos órgãos de fiscalização responsáveis e, sobretudo do fabricante/manipulador, é o principal fator determinador de qualidade/sanidade do gelado ofertado à população. 


\section{REFERÊNCIAS}

ALLATA, S.; VALERO, A.; BENHADJA, L. Implementation of traceability and food safety systems (HACCP) under the ISO 22000:2005 standard in North Africa: The case study of an ice cream company in Algeria. Food Control, v. 79, 239-253, 2017. Disponível em: < https://doi.org/10.1016/j.foodcont.2017.04.002>. doi: 10.1016/j.foodcont.2017.04.002.

BAHRAM-PARVAR, M. A review of modern instrumental techniques for measurements of ice cream characteristics. Food Chemistry, v. 188, p. 625-31, 2015. Disponível em: <https://doi.org/10.1016/j.foodchem.2015.05.017>. doi: 10.1016 / j.foodchem.2015.05.017

BALTHAZAR, C. F.; SILVA, H. L. A.; VIEIRA, A. H.; NETO, R. P. C.; CAPPATO, L. $P$., et al. Assessing the effects of different prebiotic dietary oligosaccharides in sheep milk ice cream. Food Research International, v. 91, 38-46, 2017. Disponível em: <https://doi.org/10.1016/j.foodres.2016.11.008>. doi: 10.1016/j.foodres.2016.11.008.

BRASIL. Agência Nacional de Vigilância Sanitária. Consulta Pública nํ2 28, de 01 de junho de 2000. Regulamento Técnico para Fixação de Identidade e Qualidade de Gelados Comestíveis, Preparados, Pós para o Preparo e Bases para Gelados Comestíveis. Disponível em: http://www4.anvisa.gov.br/base/visadoc/CP/CP[32171-0].PDF. Acesso em 22 setembro, 2018.

BRASIL. Agência Nacional de Vigilância Sanitária. Resolução RDC 12. Regulamento Técnico sobre Padrões Microbiológicos para Alimentos. Diário Oficial da União. 02 de Janeiro de 2001.2 Disponível em: <http://portal.anvisa.gov.br/documents/33880/2568070/RDC_12_2001.pdf/15ffddf63767-4527-bfac-740a0400829b>. Acesso em 22 setembro 2018.

BRASIL. Instrução Normativa n.62, de 26 de agosto de 2003. Métodos Analíticos Oficiais para Análises Microbiológicas Oficiais para Análises Microbiológicas para Controle de Produtos de Origem Animal e Água. Ministério da Agricultura, Pecuária e Abastecimento. Diário Oficial da União, Brasília, DF, de 18 de set. de 2003, Seção 1, p. 14.2003.

CDC. Centers for Disease Control and Prevention (2015). Multistate outbreak of listeriosis linked to Blue Bell creameries products (final update). Atlanta, GA: Centers for Disease Control and Prevention. http://www.cdc.gov/listeria/ outbreaks/ice-cream-03-15, 2015.

CLAEYS, W. L.; CARDOEN, S.; DAUBE, G.; DE BLOCK, J.; DEWETTINCK, K.; et al. Raw or heated cow milk consumption: Review of risks and benefits. Food Control, v. 31, n. 1, 251-262, 2013, 2013. Disponível em: < https://doi.org/10.1016/j.foodcont.2012.09.035>. doi: 10.1016/j.foodcont.2012.09.035.

DEOSARKAR, S. S.; KALYANKAR, S. D.; PAWSHE, R. D.; KHEDKAR, C. D. Ice cream: Composition and health effects. In: CABALLERO, B.; FINGLAS, P.; AND TOLDRÁ, F. (eds.). The Encyclopedia of Food and Health, v. 3, p. 385-390. Oxford: Academic Press, 2016.2 Disponível em: 
$<$ https://www.researchgate.net/publication/294787583_Ice_cream_Composition_and health_effects>. Acesso em: 22 setembro 2018.

FETSCH, A.; CONTZEN, M.; HARTELT, K.; KLEISER, A.; MAASSEN, S. et al. Staphylococcus aureus food-poisoning outbreak associated with the consumption of ice-cream. International Journal of Food Microbiology, v. 187, 1-6, 2014. Disponível em: < https://doi.org/10.1016/j.ijfoodmicro.2014.06.017>. doi: 10.1016/j.ijfoodmicro.2014.06.017.

FROZEN CONFECTIONS REGULATION. Chapter 132AC. 11p. 2014. Disponível em: < https://www.elegislation.gov.hk/hk/cap132AC>. Acesso em 12 setembro 2018.

ICE CREAM STANDARD. TS 4265. Turkish Standards Institute. TSE, NecatibeyAnkara, 1992. Disponível em: <http://is.smiic.org/files/PDF/1483439070-turkeytse.pdf $>$. Acesso em 22 setembro 2018.

ISI. Indian Standards Specification for Ice Cream. IS: 2802, 1964. New Delhi: Indian Standard Institutions. 1964.

KEBS. KENYA BUREAU OF STANDARDS. Specification for edible ices and ice mixes. $2013 . \quad$ Disponível em: <http://www.inmetro.gov.br/barreirastecnicas/pontofocal/..\%5Cpontofocal\%5Ctextos \%5Cregulamentos\%5CKEN_394.pdf>. Acesso em 22 setembro 2018.

MELO, J.; ANDREW, P. W.; FALEIRO, M. L. Listeria monocytogenes in cheese and the dairy environment remains a food safety challenge: The role of stress responses. Food Research International, v. 67, 75-90, 2015. Disponível em: <https://doi.org/10.1016/j.foodres.2014.10.031 >. doi: 10.1016/j.foodres.2014.10.031.

PAPADEMAS, P.; BINTSIS, T. Food safety management systems (FSMS) in the dairy industry: A review. International Journal of Dairy Technology, v. 63, n. 4, 489-503, 2010. Disponível em: < https://doi.org/10.1111/j.1471-0307.2010.00620.x>. doi: 10.1111/j.1471-0307.2010.00620.x

POUILLOT, R.; KLONTZ, K. C.; CHEN, Y.; BURALL, L. S.; MACARISIN, D., et al. Infectious dose of Listeria monocytogenes in outbreak linked to ice cream, United States, 2015. Emerging Infectious Diseases, v. 22, n. 12, 2113-2119, 2016. Disponível em: <http://dx.doi.org/10.3201/eid2212.160165>. doi: 10.3201 / eid2212.160165.

RICHARDS, N. S. P. S., SILVA, M. E., PEREIRA, D., SANTOS. F. I., FLECK, A., COUTINHO, M. P. M. D. Avaliação das condições higiênico-sanitárias de sorvetes tipo italiano (soft), comercializados na cidade de São Leopoldo-RS. Revista Higiene Alimentar, São Paulo-SP, v.16 no 92/93 Jan/Fev 2002.

SILVA, N.; JUNQUEIRA, V. C. A., SILVEIRA, N. F. A., TANIWAKI, M. H., GOMES, R. A. R., OKAZAKI, M. M. Manual de Métodos de Análises Microbiológica de Alimentos e Água. 5aㅡ. ed., São Paulo, 2017, 535 p. 
SOUKOULIS, C.; FISK, I. D.; BOHN T. Ice cream as a vehicle for incorporating health-promoting ingredients: conceptualization and overview of quality and storage stability. Comprehensive Reviews in Food Science and Food Safety, v. 13, 627655, 2014. Disponível em: < https://doi.org/10.1111/1541-4337.12083>. doi: 10.1111/1541-4337.12083 